\title{
In silico and in vitro evaluation of primers for molecular differentiation of Leishmania species
}

\author{
Avaliação in silico e in vitro de iniciadores para a diferenciação molecular de \\ espécies de Leishmania
}

Beatriz Batista Trigo1\#; Fernanda Muller de Oliveira-Rovai1\#; Marco Milanesi1,2; Pier Kenji Rauschkolb Katsuda Ito'; Yuri Tani Utsunomiya ${ }^{1,2}$; Flávia Lombardi Lopes ${ }^{1}$; Silvana de Cássia Paulan; Cáris Maroni Nunes ${ }^{1 *}$ (1)

${ }^{1}$ Faculdade de Medicina Veterinária, Universidade Estadual Paulista - UNESP, Araçatuba, SP, Brasil

${ }^{2}$ Centro Colaborador da Agência Internacional de Energia Atômica - IAEA em Genômica Animal e Bioinformática, Araçatuba, SP, Brasil

\begin{abstract}
How to cite: Trigo BB, Oliveira-Rovai FM, Milanesi M, Ito PKRK, Utsunomiya YT, Lopes FL, et al. In silico and in vitro evaluation of primers for molecular differentiation of Leishmania species. Braz J Vet Parasitol 2021; 30(1): e022020. https://doi.org/10.1590/ S1984-296120201078
\end{abstract}

\begin{abstract}
Leishmaniasis is a zoonotic disease caused by over 20 species of protozoan parasites of the genus Leishmania. Infection is commonly spread by sandflies and produces a wide spectrum of clinical signs and symptoms. Therefore, from an epidemiological and therapeutic standpoint, it is important to detect and differentiate Leishmania spp. The objective of this study was to combinate in silico and in vitro strategies to evaluate the analytical specificity of primers previously described in the literature. According to electronic PCR (e-PCR) analysis, 23 out of 141 pairs of primers selected through literature search matched their previously reported analytical specificity. In vitro evaluation of nine of these primer pairs by quantitative PCR (qPCR) confirmed the analytical specificity of five of them at the level of Leishmania spp., L. mexicana complex or Leishmania and Viannia subgenera. Based on these findings, the combination of e-PCR and GPCR is suggested to be a valuable approach to maximize the specificity of new primer pairs for the laboratory diagnosis of infections with Leishmania spp.
\end{abstract}

Keywords: Leishmaniasis, differential diagnosis, e-PCR, qPCR.

\begin{abstract}
Resumo
As leishmanioses são zoonoses causadas por mais de 20 espécies de protozoários do gênero Leishmania. As infecções são comumente disseminadas por flebotomíneos e causam um amplo espectro de manifestações clínicas. Portanto, a detecção e diferenciação de espécies de Leishmania são importantes do ponto de vista epidemiológico e terapêutico. $O$ objetivo deste estudo foi combinar estratégias in silico e in vitro para avaliar a especificidade analítica dos primers descritos anteriormente na literatura. De acordo com a PCR eletrônica (e-PCR), 23 dos 141 pares de primers selecionados por meio de pesquisa da literatura estavam de acordo com a especificidade analítica anteriormente relatada. A avaliação in vitro de nove desses pares de primers, por PCR quantitativa (qPCR), confirmou a especificidade analítica de cinco deles ao nível de espécie de Leishmania, do complexo L. mexicana ou dos subgêneros Leishmania e Viannia. Com base nos resultados, sugere-se que a combinação de e-PCR e qPCR é uma abordagem valiosa para a validação e maximização da especificidade de novos pares de primers para o diagnóstico laboratorial de infecções com Leishmania spp.
\end{abstract}

Palavras-chave: Leishmaniose, diagnóstico diferencial, e-PCR, qPCR.

Received September 17, 2020. Accepted October 22, 2020.

\#Equal contributors.

Financial support: The scholarships of Beatriz Batista Trigo and Fernanda Muller de Oliveira-Rovai were financed by Coordenação de Aperfeiçoamento de Pessoal de Nível Superior - Brasil (CAPES) - Finance Code 001. Marco Milanesi was supported by Grant No. 2016/05787-7 awarded by FAPESP, the São Paulo Research Foundation.

*Corresponding author: Cáris Maroni Nunes. E-mail: caris.nunes@unesp.br 


\section{Introduction}

Trypanosomatidae (Trypanosomatida) is a family of parasites that includes monoxenous (infect only a single invertebrate host) and dixenous (infect both a vertebrate and invertebrate host) pathogens (Maslov et al., 2019). Leishmaniasis is a zoonotic disease caused by a dixenous trypanosomatid of the genus Leishmania, transmitted to mammals by the bites of sand flies, and is a major global health problem (Akhoundi et al., 2017; Galluzzi et al., 2018; Lukeš et al., 2018). More than 20 Leishmania species produce a wide range of clinical manifestations of leishmaniasis (WHO, 2020).

In the Americas, Leishmania infantum (syn. Leishmania chagasi; subgenus Leishmania) is the main species involved in Visceral Leishmaniasis, while species of the subgenera Leishmania and Viannia are responsible for Cutaneous Leishmaniasis and Mucocutaneous Leishmaniasis. Apart from L. infantum, the Leishmania amazonensis, Leishmania mexicana and Leishmania venezuelensis species are also of clinical relevance within the subgenus Leishmania, whereas Leishmania braziliensis, Leishmania guyanensis, Leishmania panamensis and Leishmania peruviana are among the major species of the Viannia subgenus (PAHO, 2012a, b).

The detection and differentiation of Leishmania species contribute to the determination of patient prognosis and treatment and can be an invaluable tool for epidemiological surveillance (Schriefer et al., 2008; Medley et al., 2015).

Several authors have used PCR-based techniques to differentiate Leishmania species (Akhoundi et al., 2013; Morais et al., 2016; Conter et al., 2018). These molecular techniques, which include real-time quantitative polymerase chain reaction (qPCR), have provided an alternative to multilocus enzyme electrophoresis (MLEE) (Galluzzi et al., 2018), which has been considered the "gold standard" technique for the differentiation of Leishmania species (Schönian et al., 2011), and enables testing of a wide range of biological samples (blood, lymph node, bone marrow, skin, etc.). These techniques are also highly sensitive and specific, and are fast to perform (Galluzzi et al., 2018). However, their success and specificity depend on prior knowledge of target sequences (Tsokana et al., 2014).

Today, the availability of genomic information and bioinformatic tools enables one to predict PCR efficiency (Ivens et al., 2005; Cantacessi et al., 2015). In addition, in silico analyses such as electronic PCR (e-PCR) can be performed before molecular assays, saving time at no additional cost (Schuler, 1997).

In this study, we evaluated the specificity of primers described in the literature using an in silico strategy based on the genomic information available in public databases. We then conducted qPCR assays using reference strains of the main American Leishmania spp. to confirm our in silico results.

\section{Material and Methods}

\section{Selection and in silico evaluation of primers specific for Leishmania spp.}

Subgenus-specific, complex-specific and species-specific primers were selected based on previous reports (Supplementary file -Table S1). In silico evaluation was performed using the e-PCR command line tool version 2.3.12 (Schuler, 1998) and the R (R Development Core Team, 2020) statistical computing language for data handling and inspection. The dataset used in the electronic PCR step included the genomic sequences of the hosts (i.e., dog and human), vector (i.e., sand fly) and Trypanosomatidae, including dixenous and some monoxenous trypanosomatids (Supplementary file -Table S2). The data were retrieved among the available genomes present in the National Center for Biotechnology Information-NCBI (NCBI, 2018) and in TriTrypDB (TriTrypDB, 2018) databases. All the data were collected by April 2018 and combined with additional genomic sequences of the genus Leishmania obtained by our research group (SRA accession: PRJNA521679) (NCBI, 2019) also included in the Supplementary file (Table S2).

The e-PCR results consisted of all the in silico amplified sequence information in the dataset. In order to select potential candidates for further in vitro evaluation, a filtering procedure was applied using scripts developed in-house in the $\mathrm{R}$ environment, where a primer was retained if: i) it amplified a species-specific region that matched those previously reported in the literature; ii) the amplified fragment size ranged from 80 to 250 base pairs (bp) in the target species of Leishmania; iii) alignment gaps or mismatches were absent in targeted species; and iv) amplification occurred in non-targeted species, its alignment presented five or more gaps or mismatches. 


\section{In vitro evaluation of primers by real-time PCR (qPCR)}

Primer sets filtered by the aforementioned parameters were subjected to $\mathrm{QPCR}$ in order to evaluate in vitro specificity. In particular, nine reference strains of Leishmania were used: L. amazonensis (IFLA/BR/1967/PH8), L. braziliensis (MHOM/BR/1975/M2903), L. infantum (MHOM/BR/1972/LD46), L. guyanensis (MHOM/BR/1975/M4147), L. major (LV 39 MRHO/SV/59/P), L. mexicana (MHOM/BZ/1982/BEL21), L. panamensis (isolated strain in Panama in 2018), L. shawi (MCEB/BR/1984/M8408) and also a local L. infantum strain isolated in the city of Araçatuba, SP, Brazil.

DNA was extracted from cultured strains using a DNeasy Blood \& Tissue kit (Qiagen ${ }^{\circledR}$ ) according to the manufacturer's instructions. After optimizing the qPCR reaction conditions (data not shown), the assays were standardized and performed in triplicate in a Real Time IQ ${ }^{\text {TM}} 5$ (Bio-Rad ${ }^{\circledR}$ ) thermocycler. The final reaction volume was $20 \mu \mathrm{l}$ and contained between 30-50 ng of sample DNA (evaluated by a NanoDrop ${ }^{\circledR}$ ND-1000 spectrophotometer), $10 \mu \mathrm{M}$ of each primer and $10 \mu \mathrm{l}$ of Power SYBR ${ }^{\mathrm{TM}}$ Green PCR Master Mix (Applied BioSystems ${ }^{\circledR}$ ). After activation of AmpliTaq Gold ${ }^{\circledR}$ enzymes $\left(95^{\circ} \mathrm{C}\right.$ for $10 \mathrm{~min}$ ), amplification was performed at $95^{\circ} \mathrm{C}$ for $15 \mathrm{sec}$, and $60^{\circ} \mathrm{C}$ for $60 \mathrm{sec}$, in a total of 40 cycles.

Samples were run in triplicates and Ct values for each species of Leishmania and combinations of primer pairs were compared with the Ct values of the positive controls. Wilcoxon Rank-Sum test was applied, and p-values lower than the Bonferroni-corrected significance level (0.0056) were defined as negative (i.e., no amplification), while the opposite was defined as positive (i.e., amplification).

DNA samples of the aforementioned strains and the 13A/13B genus-specific primers (Rodgers et al., 1990) were used as positive controls.

\section{Results and Discussion}

This study combined in silico (e-PCR) and in vitro (qPCR) analyses to evaluate the specificity of primer pairs for molecular differentiation of Leishmania spp. Before testing primers in vitro, researchers have often used PrimerBLAST (NCBI) to predict the outcome of PCR assays. However, Primer-BLAST allows for testing only one pair of primers at a time. Therefore, e-PCR is a more powerful strategy, given that it allows for the simultaneous screening of primers, which enabled us to narrow the test list down.

A total of 141 pairs of primers mined from the literature and described as species-, complex-, subgenus- or genus-specific were evaluated for their specificity while amplifying Leishmania DNA (Table S1). e-PCR evaluations resulted in positive in silico amplifications for 94 of these primer pairs (66.7\%), of which only $36(25.5 \%)$ matched their expected specificity. After filtering, 23 primer pairs (16.3\%) met the selection criteria described in the material and methods section. Out of these, we prioritized the test of nine pairs covering species of primary interest in Brazil for in vitro testing by $\mathrm{qPCR}$. The results of five of these pairs (55.5\%) were in agreement with previous reports (Table 1) (Supplementary file - Figure S1).

In our study, the in silico and in vitro test results confirmed that ISVB-ISVC primers are specific for L. braziliensis (Castilho et al., 2003). Also, the specificity of primers 11H, 6F and B6F was confirmed for the subgenus Viannia, corroborating the findings of Oddone et al. (2009).

Primers G6PD-LLF/G6PD-LLR, previously mentioned as specific for the subgenus Leishmania (Castilho et al., 2008), showed specificity for the L. mexicana complex, amplifying a DNA fragment present in L. mexicana and L. amazonensis.

Primers b1-b2 amplified L. braziliensis DNA by e-PCR and by qPCR, as previously reported (Mimori et al., 1998). However, in the qPCR test L. shawi DNA was also amplified. As L. shawi is one of the species belonging to the subgenus Viannia, this pair of primers was not considered species-specific but only subgenus specific.

MLF-MLR primers (Ceccarelli et al., 2014) did not succeed in differentiating the subgenera Leishmania and Viannia by either e-PCR or qPCR. However, Ceccarelli et al. (2014) reported that these primers enable subgenus differentiation when amplification is followed by high resolution melting (HRM) analysis, which we did not perform. Thus, without HRM analysis, we suggest the use of this primer set in QPCR solely for genus-specific analysis.

Although the electronic PCR amplification of LEISH1-LEISH2 primers corroborated the literature in indicating the primer pair as specific for $L$. infantum (Francino et al., 2006), by qPCR we observed DNA amplification of $L$. infantum, L. guyanensis, L. major, L. mexicana and L. shawi species.

Primers Mary-f/Mary-r, which were developed to quantify L. infantum in biological specimens using kinetoplast DNA (kDNA) as the molecular target (Mary et al., 2004), showed a non-specific pattern in this study. This lack of 


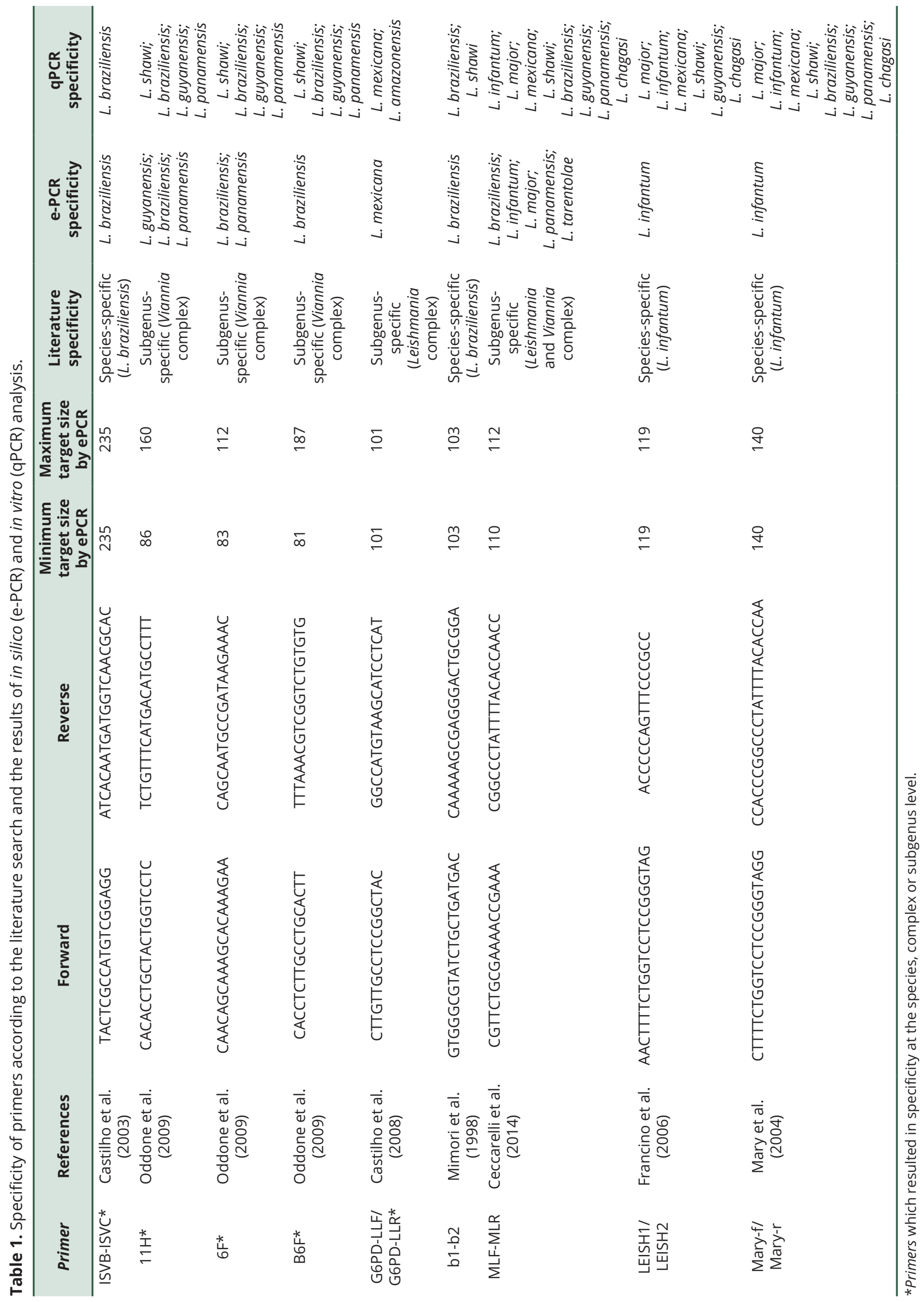


specificity confirms the findings reported by Ceccarelli et al. (2014), who evaluated the same primers and observed DNA amplification of the species L. amazonensis, L. braziliensis, L. guyanensis, L. infantum and L. panamensis. Although kDNA is a good target for sensitive detection of Leishmania spp. its specificity is low due to the fact that kDNA are small circular molecules of DNA presenting different subclasses, with high conserved regions and copy number (Ceccarelli et al., 2017; Kocher et al., 2018). PCR and qPCR techniques using kDNA targets have already shown to result in amplification of DNA fragment in more than one species of Leishmania (Ceccarelli et al., 2014, 2017; Losada-Barragán et al., 2016).

Until recently, maxicircle kDNA of many species of Leishmania were not completely sequenced. Although nextgeneration sequencing has increasingly being used for nuclear genome assembly, few works used this technology to study Leishmania mitochondrial genomes (Simpson et al., 2015; Camacho et al., 2019; Kaufer et al., 2019; Urrea et al., 2019) This lack of kDNA genomic information may be a limitation for in silico analysis.

It should be noted that primers that showed specificity by e-PCR, as reported in the literature, but were not selected for further qPCR evaluation because they did not meet the criteria established in this study, should not be discarded. For instance, we selected the optimal DNA product size range to run qPCR (Tevfik Dorak, 2006). However, primers with product sizes larger than the chosen upper limit could work in conventional PCR. The number of gaps and mismatches may also influence the success of the analysis. In this study, the absence of gaps or mismatches in the alignments by e-PCR with the target species of Leishmania was chosen to limit the results to more specific alignments. Indeed, a single mismatch near the 3 ' end positions could have a severe impact on amplification (Bru et al., 2008). Primers with less than five gaps and mismatches in alignment with other sequences of species of Leishmania were excluded to avoid possible non-specific alignment during qPCR.

Although the e-PCR was conducted using genomes collected until April 2018, we searched for updates in August 2020 and no new species have been added to the database used here (NCBI and TriTrypDB). In addition, the lack of genomic information in the public and private databases influences the rate of false positive (i.e., no amplification on non-target species) and false negative (i.e., no amplification on target species) results. However, increasing the availability of genomic information in public databases (Akhoundi et al., 2017) should favor future studies. This study shows that e-PCR is an extremely useful tool for both time and resources optimization in the design of hybridization- and amplification-based assays.

Another important fact is that, although qPCR is known to be highly sensitive and specific (Galluzzi et al., 2018), there are some conditions that cannot be controlled to the same extent as in e-PCR, and some clear examples of this are the number of gaps and mismatches.

We conducted qPCR assays using only the main American Leishmania reference strains to evaluate our in silico results. However, additional strains should also be tested to ensure the specificity of species present in other regions.

The results obtained in this study demonstrate the advantage of evaluating a set of primers in silico prior to in vitro analysis. This evaluation enabled us to rapidly identify numerous primers with the desired specificity. However, the in silico and in vitro analysis showed divergent results, which may be explained by the threshold definition in the filtering step, by the current lack of genomic information in the databases, and/or by the small number of Leishmania strains tested. Nevertheless, compared to the time and resources needed to test the full set of primers in vitro, the new approach proposed herein greatly increases efficiency in the design of candidate primers, even if false positive and false negative primers may occasionally occur.

Primers previously reported and analyzed in this study to identify Leishmania at subgenus-, complex-and speciesspecific level could be used for differentiating Leishmania spp. not only to improve diagnosis performance but also in biodiversity analysis. Currently, DNA metabarcoding has been used for the detection of targeted species in environmental samples. Since metabarcoding protocols include PCR-based enrichment of specific DNA fragments that are found in the species of interest (D'Avila-Levy et al., 2015), the set of primers here evaluated could be also used in DNA metabarcoding given they can differentiate a genus and/or species.

Given the fact that the genus Leishmania has many species and specific diagnosis may be essential the strategy used in this study, i.e., performing in silico analysis by e-PCR followed by qPCR, drastically reduced the cost and time needed to identify primers with the desired specificity. As the volume of genomic information grows at an astonishing speed, this methodology is also recommended for the optimization of molecular analysis for any species. 


\section{Acknowledgements}

We thank FIOCRUZ (Fundação Oswaldo Cruz), the research groups of Dr. Valéria Marçal Felix de Lima at the School of Veterinary Medicine of Araçatuba (UNESP), Dr. José Ângelo Lauletta Lindoso, Dr. Kelly Kanunfre and MSc Edite Hatsumi Kanashiro at the Institute of Tropical Medicine of São Paulo (USP), Dr. Vânia da Matta at the Faculty of Medicine (USP), and Dr. Azael Saldanã at Departamento de Investigación en Parasitología Molecular of Instituto Conmemorativo Gorgas de Estudios de la Salud from Panama for the reference strains employed in the experiment. We also thank Dr. Najib El-Sayed at University of Maryland Institute for Advanced Computer Studies, Flávia Florêncio de Athayde for their assistance in some of the analyses carried out in this study and Dr. Sarita Priscila Gobbo Ferrari for helping us to obtain some of the abovementioned Leishmania strains.

\section{References}

Akhoundi M, Downing T, Votýpka J, Kuhls K, Lukes J, Cannet A, et al. Leishmania infections: molecular targets and diagnosis. Mol Aspects Med 2017; 57: 1-29. http://dx.doi.org/10.1016/j.mam.2016.11.012. PMid:28159546.

Akhoundi M, Hajjaran H, Baghaei A, Mohebali M. Geographical distribution of Leishmania species of human cutaneous leishmaniasis in Fars Province, Southern Iran. Iran J Parasitol 2013; 8(1): 85-91. PMid:23682265.

Bru D, Martin-Laurent F, Philippot L. Quantification of the detrimental effect of a single primer-template mismatch by realtime PCR using the 16S rRNA gene as an example. App/ Environ Microbio/ 2008; 74(5): 1660-1663. http://dx.doi.org/10.1128/ AEM.02403-07. PMid:18192413.

Camacho E, Rastrojo A, Sanchiz Á, González-de la Fuente S, Aguado B, Requena JM. Leishmania mitochondrial genomes: maxicircle structure and heterogeneity of minicircles. Genes (Basel) 2019; 10(10): 758. http://dx.doi.org/10.3390/genes10100758. PMid:31561572.

Cantacessi C, Dantas-Torres F, Nolan MJ, Otranto D. The past, present, and future of Leishmania genomics and transcriptomics. Trends Parasitol 2015; 31(3): 100-108. http://dx.doi.org/10.1016/j.pt.2014.12.012. PMid:25638444.

Castilho TM, Shaw JJ, Floeter-Winter LM, Camargo LMA, McMahon-Pratt D. A real-time polymerase chain reaction assay for the identification and quantification of American Leishmania species on the basis of glucose-6-phosphate-dehydrogenase. Am J Trop Med Hyg 2008; 78(1): 122-132. http://dx.doi.org/10.4269/ajtmh.2008.78.122. PMid:18187795.

Castilho TM, Shaw JJ, Floeter-Winter LM. New PCR assay using glucose-6-phosphate dehydrogenase for identification of Leishmania species. J Clin Microbio/ 2003; 41(2): 540-546. http://dx.doi.org/10.1128/JCM.41.2.540-546.2003. PMid:12574243.

Ceccarelli M, Galluzzi L, Diotallevi A, Andreoni F, Fowler H, Petersen C, et al. The use of kDNA minicircle subclass relative abundance to differentiate between Leishmania (L.) infantum and Leishmania (L.) amazonensis. Parasit Vectors 2017; 10(1): 239. http://dx.doi. org/10.1186/s13071-017-2181-x. PMid:28511704.

Ceccarelli M, Galluzzi L, Migliazzo A, Magnani M. Detection and characterization of Leishmania (Leishmania) and Leishmania (Viannia) by SYBR green-based real-time PCR and high-resolution melt analysis targeting kinetoplast minicircle DNA. PLoS One 2014; 9(2): e88845. http://dx.doi.org/10.1371/journal.pone.0088845. PMid:24551178.

Conter CC, Lonardoni MVC, Aristides SMA, Cardoso RF, Silveira TGV. New primers for the detection Leishmania species by multiplex polymerase chain reaction. Parasitol Res 2018; 117(2): 501-511. http://dx.doi.org/10.1007/s00436-017-5726-1. PMid:29280072.

d'Avila-Levy CM, Boucinha C, Kostygov A, Santos HLC, Morelli KA, Grybchuk-leremenko A, et al. Exploring the environmental diversity of kinetoplastid flagellates in the high-throughput DNA sequencing era. Mem Inst Oswaldo Cruz 2015; 110(8): $956-965$. http://dx.doi.org/10.1590/0074-02760150253. PMid:26602872.

Francino O, Altet L, Sánchez-Robert E, Rodriguez A, Solano-Gallego L, Alberola J, et al. Advantages of real-time PCR assay for diagnosis and monitoring of canine leishmaniosis. Vet Parasitol 2006; 137(3-4): 214-221. http://dx.doi.org/10.1016/j. vetpar.2006.01.011. PMid:16473467.

Galluzzi L, Ceccarelli M, Diotallevi A, Menotta M, Magnani M. Real-time PCR applications for diagnosis of leishmaniasis. Parasit Vectors 2018; 11(1): 273. http://dx.doi.org/10.1186/s13071-018-2859-8. PMid:29716641.

Ivens AC, Peacock CS, Worthey EA, Murphy L, Aggarwal G, Berriman M, et al. The genome of the kinetoplastid parasite, Leishmania major. Science 2005; 309(5733): 436-442. http://dx.doi.org/10.1126/science.1112680. PMid:16020728.

Kaufer A, Barratt J, Stark D, Ellis J. The complete coding region of the maxicircle as a superior phylogenetic marker for exploring evolutionary relationships between members of the Leishmaniinae. Infect Genet Evo/ 2019; 70: 90-100. http://dx.doi.org/10.1016/j. meegid.2019.02.002. PMid:30738194.

Kinetoplastid Informatics Resources - TriTrypDB. Kinetoplastid informatics resources [online]. 2018 [cited 2020 Mar 10]. Available from: https://tritrypdb.org/tritrypdb/app 
Kocher A, Valière S, Bañuls AL, Murienne J. High-throughput sequencing of kDNA amplicons for the analysis of Leishmania minicircles and identification of Neotropical species. Parasitology 2018; 145(5): 585-594. http://dx.doi.org/10.1017/S0031182017002013. PMid:29144208.

Losada-Barragán M, Cavalcanti A, Umaña-Pérez A, Porrozzi R, Cuervo-Escobar S, Vallejo AF, et al. Detection and quantification of Leishmania infantum in naturally and experimentally infected animal samples. Vet Parasitol 2016; 226: 57-64. http://dx.doi. org/10.1016/j.vetpar.2016.05.022. PMid:27514885.

Lukeš J, Butenko A, Hashimi H, Maslov DA, Votýpka J, Yurchenko V. Trypanosomatids are much more than just Trypanosomes: clues from the expanded family tree. Trends Parasito/ 2018; 34(6): 466-480. http://dx.doi.org/10.1016/j.pt.2018.03.002. PMid:29605546.

Mary C, Faraut F, Lascombe L, Dumon H. Quantification of Leishmania infantum DNA by real-time PCR assay with high sensitivity. J Clin Microbiol 2004; 42(11): 5249-5255. http://dx.doi.org/10.1128/JCM.42.11.5249-5255.2004. PMid:15528722.

Maslov DA, Opperdoes FR, Kostygov AY, Hashimi H, Lukeš J, Yurchenko V. Recent advances in trypanosomatid research: genome organization, expression, metabolism, taxonomy and evolution. Parasitology 2019; 146(1): 1-27. http://dx.doi.org/10.1017/ S0031182018000951. PMid:29898792.

Medley GF, Hollingsworth TD, Olliaro PL, Adams ER. Health-seeking behavior, diagnostics and transmission dynamics in the control of visceral leishmaniasis in the Indian subcontinent. Nature 2015; 528(7580): S102-S108. http://dx.doi.org/10.1038/ nature16042. PMid:26633763.

Mimori T, Sasaki JI, Nakata M, Gomez EA, Uezato H, Nonaka S, et al. Rapid identification of Leishmania species from formalin-fixed biopsy samples by polymorphism-specific polymerase chain reaction. Gene 1998; 210(2): 179-186. http://dx.doi.org/10.1016/ S0378-1119(97)00663-X. PMid:9573358.

Morais RC, da Costa Oliveira CN, de Albuquerque SC, Mendonça Trajano Silva LA, Pessoa-E-Silva R, Alves da Cruz HL, et al. Realtime PCR for Leishmania species identification: evaluation and comparison with classical techniques. Exp Parasitol 2016; 165: 43-50. http://dx.doi.org/10.1016/j.exppara.2016.03.005. PMid:26968776.

National Center for Biotechnology Information - NCBI. [online]. 2018 [cited 2020 Mar 10]. Available from: https://www.ncbi. nIm.nih.gov/

National Center for Biotechnology Information - NCBI. Sequence Read Archive (SRA) data [online]. 2019 [cited 2020 Mar 10]. Available from: https://www.ncbi.nlm.nih.gov/sra/PRJNA521679

Oddone R, Schweynoch C, Schönian G, de Sousa CS, Cupolillo E, Espinosa D, et al. Development of a multilocus microsatellite typing approach for discriminating strains of Leishmania (Viannia) species. J Clin Microbio/ 2009; 47(9): 2818-2825. http://dx.doi. org/10.1128/JCM.00645-09. PMid:19587302.

Pan American Health Organization - PAHO. General information: visceral leishmaniasis [online]. Washington: PAHO; 2012a [cited 2020 Feb 15]. Available from: https://www.paho.org/hq/index.php?option=com_content\&view=article\&id=6420:2012leishmaniasis-visceral\&Itemid=39347\&lang=en

Pan American Health Organization - PAHO. Cutaneous and mucosal leishmaniasis [online]. Washington: PAHO; $2012 \mathrm{~b}$ [cited 2020 Feb 15]. Available from: https://www.paho.org/hq/index.php?option=com_content\&view=article\&id=6417:2012-leishmaniasiscutanea-mucosa\&ltemid=39345\&lang=en

R Development Core Team. R: a language and environment for statistical computing [online]. Vienna: R Foundation for Statistical Computing; 2020 [cited 2020 Feb 10]. Available from: http://www.R-project.org/

Rodgers MR, Popper SJ, Wirth DF. Amplification of kinetoplast DNA as a tool in the detection and diagnosis of Leishmania. Exp Parasitol 1990; 71(3): 267-275. http://dx.doi.org/10.1016/0014-4894(90)90031-7. PMid:2170165.

Schönian G, Kuhls K, Mauricio IL. Molecular approaches for a better understanding of the epidemiology and population genetics of Leishmania. Parasitology 2011; 138(4): 405-425. http://dx.doi.org/10.1017/S0031182010001538. PMid:21078222.

Schriefer A, Wilson ME, Carvalho EM. Recent developments leading toward a paradigm switch in the diagnostic and therapeutic approach to human leishmaniasis. Curr Opin Infect Dis 2008; 21(5): 483-488. http://dx.doi.org/10.1097/QCO.0b013e32830d0ee8. PMid:18725797.

Schuler GD. Electronic PCR: bridging the gap between genome mapping and genome sequencing. Trends Biotechno/ 1998; 16(11): 456-459. http://dx.doi.org/10.1016/S0167-7799(98)01232-3. PMid:9830153.

Schuler GD. Sequence mapping by electronic PCR. Genome Res 1997; 7(5): 541-550. http://dx.doi.org/10.1101/gr.7.5.541. PMid:9149949.

Simpson L, Douglass SM, Lake JA, Pellegrini M, Li F. Comparison of the mitochondrial genomes and steady state transcriptomes of two strains of the Trypanosomatid parasite, Leishmania tarentolae. PLoS Neg/ Trop Dis 2015; 9(7): e0003841. http://dx.doi. org/10.1371/journal.pntd.0003841. PMid:26204118. 
Differentiation of Leishmania species

Tevfik Dorak M. Real-time PCR: BIOS advanced methods. New York: Ed. Taylor \& Francis; 2006.

Tsokana CN, Athanasiou LV, Valiakos G, Spyrou V, Manolakou K, Billinis C. Molecular diagnosis of leishmaniasis, species identification and phylogenetic analysis. In: Claborn D. Leishmaniasis: trends in epidemiology, diagnosis and treatment. London: Intech Open; 2014. p. 161-193. https://doi.org/10.5772/57448.

Urrea DA, Triana-Chavez O, Alzate JF. Mitochondrial genomics of human pathogenic parasite Leishmania (Viannia) panamensis. PeerJ 2019; 7: e7235. http://dx.doi.org/10.7717/peerj.7235. PMid:31304069.

World Health Organization - WHO. Leishmaniasis [online]. Geneva: WHO; 2020 [cited 2020 Mar 10]. Available from: http://www. who.int/mediacentre/factsheets/fs375/en/ 


\section{Supplementary files}

Supplementary material accompanies this paper.

Table S1. Table list of pairs of species-, subgenus-, complex- or genus-specific primers described in the literature and details of their amplification.

Table S2. Table of information about the dataset used in the electronic PCR step including the genomic sequences information of dog, human, sand fly and trypanosomatids.

Figure S1. Box plot of the DNA fragment amplifications of Leishmania spp. by qPCR according to Ct values. Positive controls are represented in blue, negative controls in black, samples considered positive in green, and negative in red.

This material is available as part of the online article from http://www.scielo.br/rbpv 